Der Teufel und seine poietische Macht in literarischen Texten vom Mittelalter zur Moderne 



\section{Der Teufel und seine poietische Macht in literarischen Texten vom Mittelalter zur Moderne}

Herausgegeben von

Jutta Eming und Daniela Fuhrmann 
Gedruckt mit freundlicher Unterstützung des edocs-Programms der Freien Universität Berlin sowie des Graduate Campus der Universität Zürich.

ISBN 978-3-11-066717-2

e-ISBN (PDF) 978-3-11-066718-9

e-ISBN (EPUB) 978-3-11-066735-6

DOI https://doi.org/10.1515/9783110667189

\section{(cc) BY-NC-ND}

Dieses Werk ist lizensiert unter einer Creative Commons Namensnennung - Nicht-kommerziell Keine Bearbeitung 4.0 International Lizenz. Weitere Informationen finden Sie unter http://creativecommons.org/licenses/by-nc-nd/4.0/.

\section{Library of Congress Control Number: 2020943237}

\section{Bibliografische Information der Deutschen Nationalbibliothek}

Die Deutsche Nationalbibliothek verzeichnet diese Publikation in der Deutschen Nationalbibliografie; detaillierte bibliografische Daten sind im Internet über http://dnb.dnb.de abrufbar.

(C) 2021 Jutta Eming, Daniela Fuhrmann, publiziert von Walter de Gruyter GmbH, Berlin/Boston.

Dieses Buch ist als Open-Access-Publikation verfügbar über www.degruyter.com.

Umschlagabbildung: Versuchung Christi (1480/82), Michael Pacher, St. Wolfgang/Österreich; Institut für Realienkunde - Universität Salzburg

https://realonline.imareal.sbg.ac.at/detail/?archivnr $=004763$

Satz: Integra Software Services Pvt. Ltd.

Druck und Bindung: CPI books GmbH, Leck

www.degruyter.com 